\begin{abstract}
BACKGROUND and aim: Morphine co-injection has anti-inflammatory effects on zymosan-induced peritonitis in several strains of mice except that of CBA. As peritoneal mast cells (pMCs) are much more numerous in CBA mice than in SWISS mice, the role of pMCs in morphine-modulated zymosan peritonitis is compared in CBA and SWISS males.

Methods: pMCs were treated in vitro with morphine or $\mathrm{C} 48 / 80$ for comparison of histamine release. In vivo accumulation of leukocytes and histamine in peritoneal exudate were recorded after intraperitoneal injection with morphine, zymosan, or zymosan plus morphine.

Results and conclusion: Morphine induces histamine release by pMCs from CBA mice but not SWISS mice. In vivo morphine-induced peritonitis is stronger in CBA mice than SWISS mice. Corollary, morphine antiinflammatory effects on zymosan peritonitis are reversed in CBA mice by its pro-inflammatory action through CBA pMCs.
\end{abstract}

Key words: Peritoneal inflammation, Peritoneal mast cells, Histamine, Morphine, C48/80

\section{Mast cells are responsible for the lack of anti-inflammatory effects of morphine in CBA mice}

\author{
Elzbieta Stankiewicz, Ewa Wypasek and \\ Barbara Plytycz ${ }^{\mathrm{CA}}$
}

Department of Evolutionary Immunobiology, Institute of Zoology, Jagiellonian University, R.Ingardena 6, PL 30-060 Krakow, Poland

\author{
${ }^{\mathrm{CA}}$ Corresponding Author \\ Tel: +48126632428 \\ Fax: +48126343716 \\ E-mail: plyt@zuk.iz.uj.edu.pl
}

\section{Introduction}

Experimental peritonitis induced in mice by intraperitoneal (i.p.) zymosan injection makes it possible to easily monitor behavioural symptoms of pain and precisely quantify inflammation-related cells and soluble factors in samples of peritoneal exudate. For these reasons such a model of inflammation is convenient for investigations of a modulatory action of various factors on the course of inflammation, including effects of morphine, a well-known antinociceptive drug. We have previously shown that characteristic body writhes, considered to be pain symptoms in zymosan-injected individuals, are completely absent in mice co-injected with morphine. The low dose of morphine $(5 \mathrm{mg} / \mathrm{kg}$ of body weight) attenuated pain in all the investigated strains of mice, while only the high dose of morphine (20 $\mathrm{mg} / \mathrm{kg}$ of body weight) additionally inhibited the early stages of i.p. accumulation of exudatory leukocytes in most strains $(\mathrm{C} 57 \mathrm{C} 3 \mathrm{H}$, SWISS, Balb/c, C57BL $/ 6)^{1,2}$ but not CBA. ${ }^{2}$ Anti-inflammatory effects of morphine might be advantageous during planned surgeries, but we should know why such effects are not universal even among various strains of the same species

The main aim of the present study is to find out the reason(s) for the insensitivity of CBA mice to antiinflammatory effects of the high dose of morphine. During previous experiments on the murine peritonitis we recorded that the strains investigated by our team differed in the number of peritoneal mast cells
(pMCs), which were more numerous in the order SWISS $<$ OUTBRED $<\mathrm{C} 57 \mathrm{BL}<\mathrm{Balb} / \mathrm{c}<\mathrm{CBA}^{3}$ In the light of the critical role of mast cells in inflammation, ${ }^{4}$ those results prompted us to study the effects of mast cell depletion on the subsequent zymosan-induced peritonitis in animals with the extreme low and high numbers of pMCs (i.e. in SWISS and CBA strains, respectively). After a single i.p. injection of mast cell degranulator, compound 48/80, a subsequent zymosan-induced peritonitis was inhibited in SWISS mice (as previously described by Ajuebor et $a l^{5}$ ) but enhanced in CBA mice. In the latter strain, C48/80induced mast cell degranulation was accompanied by concomitant mast cell influx and/or local proliferation, leading to drastic inter-strain differences in the peritoneal microenvironment at the time of zymosan injection. ${ }^{3}$ Therefore we put forward a hypothesis that the inter-strain differentiation in pMC numbers and characteristics might also be responsible for different responses to supplementation of peritonitis-inducing agent with morphine. It turned out that, indeed, in contrast to the pMCs of SWISS mice, the CBA pMCs are not only much more numerous, but also very sensitive to morphine-induced histamine release and the induction of inflammatory response.

\section{Methods}

Swiss males and CBA males (6-8 weeks old, 25-28 g) were purchased from the Animal Department of 
Collegium Medicum (Kraków, Poland). All mice were housed four per cage in the laboratory room with fixed light-darkness conditions (12:12 h), with water and standard diet ad libitum. The experiments were conducted according to license no. 16/OP/2001 from the Local Ethical Committee.

Swiss mice and CBA mice were either untreated (intact controls) or i.p.-injected with morphine (M group, $20 \mathrm{mg} / \mathrm{kg}$ of body weight; morphine chloride; Polfa, Kutno, Poland), with zymosan (ZM group, $2 \mathrm{mg} / \mathrm{ml}, 0.5 \mathrm{ml} /$ mice; Sigma Chemical, St Louis, MO, USA), or zymosan supplemented with morphine (ZM group). Animals were killed by cervical dislocation at time 0 (controls) or after 30 min, $4 \mathrm{~h}$ or $8 \mathrm{~h}$ after i.p. injection, and their peritoneal exudate was retrieved as described previously. ${ }^{6}$ Following centrifugation, exudatory fluid was used for measurement of histamine content by enzymelinked immunosorbent assay (ICM Pharmaceuticals, Inc., Cost Mesa, CA, USA), while Türk-stained exudatory cells were counted in a hemocytometer and used for differential counts on MGG-stained cytospin preparations.

Peritoneal cells from some intact animals were prepared for an in vitro incubation of either a total pool of PTLs ${ }^{7}$ or purified pMCs. ${ }^{8}$ In both instances the cells were adjusted to approximately 70,000 pMCs/ml and incubated in tubes with various concentrations of C $48 / 80^{8}$ or morphine (see later Fig. 2). After $45 \mathrm{~min}$ incubation and centrifugation $(10 \mathrm{~min}$ at $400 \times g)$ the cell degranulation was assessed morphologically according to Levi-Schaffer et al. ${ }^{9}$ on safraninestained ${ }^{10}$ cytospin preparations, while the percentage of histamine released to supernatant was assessed and calculated according to Verbsky et al.' ${ }^{11}$ formula: $\%$ histamine released $=$ (histamine released by the inducer/total histamine content $) \times 100$. The results were analysed by analysis of variance and Student's $t$-test.

\section{Results and discussion}

The results of the in vivo part of the present experiments are shown in Fig. 1. Comparison of the modulatory effect of morphine during the initial $8 \mathrm{~h}$ of zymosan-induced peritonitis in the SWISS and CBA mice is given on the left-hand side of Fig. 1. In both investigated strains of mice a zymosan-induced peritoneal inflammation is connected with a massive intraperitoneal accumulation of polymorphonuclear leukocytes (PMNs), apparently absent before a zymosan injection, with a peak $4 \mathrm{~h}$ after the injection. In full concordance with our previous results, at this time point the PMN accumulation in the ZM group of animals was significantly inhibited in SWISS mice ${ }^{1,2}$ while it was unaffected in CBA mice. ${ }^{2}$ However, the present results show additionally that in the ZM group of SWISS mice the PMN accumulation continued thus at $8 \mathrm{~h}$ after the injection and was similar in the $Z$ and $Z M$ groups. At that time the PMN accumulation was already diminished in the $Z$ group but not the ZM group of the CBA strain of animals (Fig. 1, left).

In attempts to find out the reasons for the difference in the modulatory effect of morphine on zymosan-induced peritonitis between the SWISS and CBA mice, we compared the early events of peritonitis evoked in the two strains by morphine only. In both strains an i.p. morphine injection was immediately followed by a significant influx of PMNs, which was short-lasting in the SWISS mice while in CBA mice it persisted for at least $4 \mathrm{~h}$ (Fig. 1, top right). The number of pMCs, which was significantly higher in the intact CBA than SWISS animals, in the former was additionally increased by i.p. morphine injection (Fig. 1 , middle right). This was accompanied by a sharp and long-lasting increase in histamine level in the CBA mice, while in the SWISS mice the histamine level rose slowly. It is worth stressing that in the CBA mice the initial level of histamine (time 0) was high, perhaps due to mechanical manipulations during exudate retrieval, while in the SWISS mice it was close to zero (Fig. 1, bottom right).

Figure 2 shows the results of the in vitro part of our experiments, when the same numbers of CBA and SWISS-derived pMCs were incubated with either the control mast cell degranulator, compound $\mathrm{C} 48 / 80^{8}$ or morphine. The interstrain differences were already visible in the control samples incubated in medium only, as the percentage of spontaneous histamine release was much higher in the CBA mice than in the SWISS mice $(57 \%$ and $21 \%$, respectively). Compound $\mathrm{C} 48 / 80$ induced further histamine release and pMC degranulation in both strains in a dosedependent manner (Fig. 2, right), while morphine induced a dose-dependent histamine release from the CBA pMCs only. No dose of morphine triggered histamine release from the SWISS pMCs (Fig. 2, left). The patterns of response to both agents were almost identical in the case of the same numbers of purified pMCs and those within the pool of peritoneal leukocytes (PTLs) (data not shown). In both instances the histamine release corresponded with pMC degranulation assessed by microscopic observations of pMCs with 'empty' granules and/or those expelled out of the cells.

The results of experiments presented here show that the SWISS and CBA mice differ not only in the number of pMCs, but also in the quality of these cells. In contrast to the SWISS pMCs, which are relatively more stable, the pMCs of the CBA strain are susceptible to morphine-induced as well as spontaneous degranulation and histamine release. The mast cells of the CBA animals are perhaps more mobile 

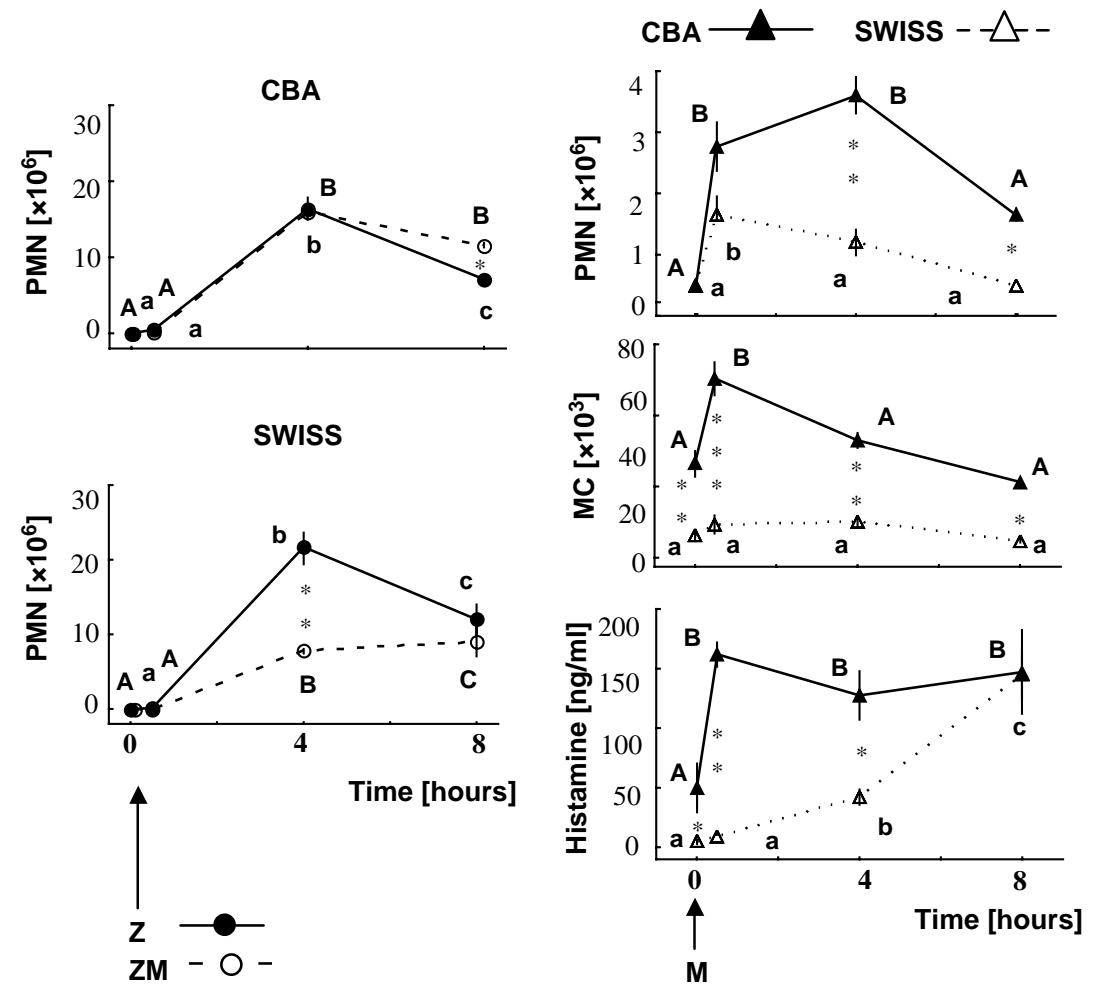

FIG. 1. Comparison of early stages of peritonitis in males of CBA and SWISS mice intraperitoneally injected with zymosan (Z group), zymosan supplemented with morphine (ZM group) or morphine only (M group). Numbers of peritoneal polymorphonuclear leukocytes (PMNs), mast cells (MC) or histamine levels at time 0 (controls) or $30 \mathrm{~min}, 4 \mathrm{~h}$ and $8 \mathrm{~h}$ after injection. Data presented as mean \pm standard error $(n=4-6)$. Values with the same letter (e.g. ' $A$ ' and ' $A$ ', ' $b$ ' and ' $b$ ') do not differ significantly within the group, while values with different letters (e.g. ' $A$ ' versus ' $B$ ', ' $a$ ' versus ' $b$ ') vary significantly within the group at $p<$ 0.05 . Values significantly different between the groups: ${ }^{*} p<0.05,{ }^{* *} p<0.01,{ }^{* * *} p<0.001$.

than those of the SWISS mice, as indicated by the fast i.p. mast cell influx after a morphine injection in the former strain. Comparative studies on leukocyte mobility and on the quantity and quality of chemotactic factors operating in these two strains are in progress. So far we may conclude that morphine acts as a strong pro-inflammatory agent in the CBA mice, since it induces pMC degranulation and histamine release, which result in a morphine-induced peritonitis much more pronounced than that evoked in the SWISS mice by the same treatment.

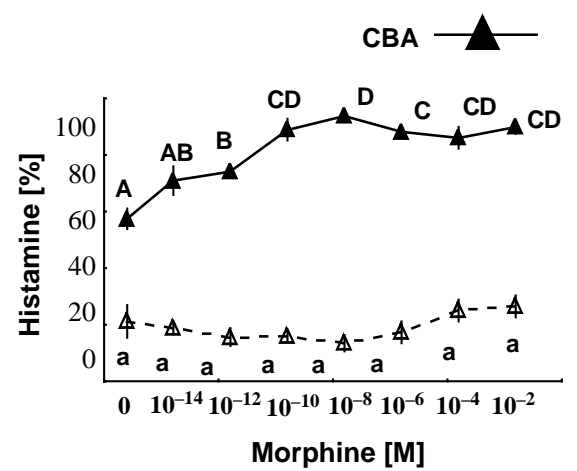

Such a CBA-specific pro-inflammatory action of morphine may at least partly explain the lack of its anti-inflammatory action when added to an irritant (zymosan) intraperitoneally injected in animals of this particular strain of mice. The anti-inflammatory effects of morphine recorded so far not only in all the other strains of mice, ${ }^{1,2}$ but also in fish, Atlantic salmon ${ }^{6}$ and goldfish, ${ }^{12}$ seem to be connected with the inhibition of leukocyte migration into the focus of inflammation caused by the desensitization of their receptors to some chemotactic factors. ${ }^{13}$ It seems that

$$
\text { swiss }-\triangle-
$$

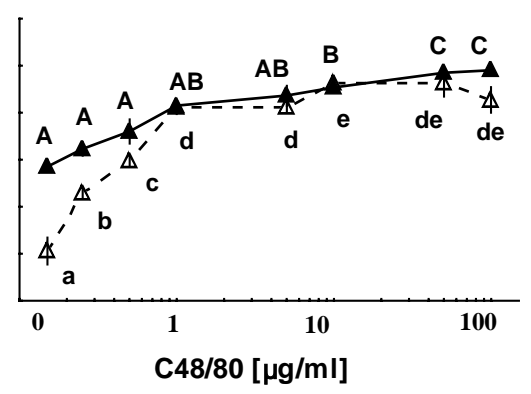

FIG. 2. In vitro effects of various doses of morphine or $\mathrm{C} 48 / 80$ on the percentage of histamine released from peritoneal mast cells of males from CBA and SWISS mice. Data presented as mean \pm standard error $(n=4)$. Values sharing at least one letter (e.g. ' $A$ ' and ' $A B^{\prime}$ ', ' $a$ ' and ' $a$ ', ' $d$ ' and 'dc') do not differ significantly within the group, while values with different letters (e.g. ' $A$ ' versus ' $B$ ', ' $c$ ' versus ' $d$ ') only vary significantly within the group at $p<0.05$. 
in the case of the CBA strain such anti-inflammatory effects are efficiently counterbalanced by morphine pro-inflammatory effects realized mainly through the highly morphine-sensitive mast cells of this strain.

The lack of anti-inflammatory effects of morphine on experimental peritonitis has been recorded also in several species of anuran amphibians (toads and frogs). This may be due to the high levels of their unique endogenous opioids, deltorphins and dermorphins. ${ }^{14}$ On the other hand, strain-specific differences in morphine effects on various components of the murine immune system have also been recorded by other investigators. ${ }^{15}$ Therefore we may conclude that the final results of morphine administration on the immune system are dependent on the balance of various (often contradictory) genetic, internal, and exogenous factors.

ACKNOWLEDGEMENTS. This study was supported by the grant 6P04C 047 21 from the State Committee for Scientific Research, Warszawa, Poland.

\section{References}

1. Plytycz B, Natorska J. Morphine attenuates pain and prevents inflammation in experimental peritonitis. Trends Immunol 2002; 23: 340-341.

2. Natorska J, Plytycz B. Strain specific dissociation in the modulatory effects of morphine on zymosan-induced peritoneal inflammation in mice. NeuroImmunoModulation 2004; submitted.

3. Stankiewicz E, Wypasek E, Plytycz B. Opposite effects of mast cell degranulation by compound $48 / 80$ on peritoneal inflammation in Swiss and CBA mice. Pol J Pharmacol 2001; 53: 149-155.

4. Kolaczkowska E, Seljelid R, Plytycz B. Critical role of mast cells in morphine-mediated impairment of zymosan-induced peritonitis in mice. Inflamm Res 2001; 50: 415-421.
5. Ajuebor MN, Das AM, Virag L, Flower RJ, Szabo C, Perretti M. Role of resident peritoneal macrophages and mast cells in chemokine production and neutrophil migration in acute inflammation: evidence for an inhibitory loop involving endogenous IL-10. J Immunol 1999; 162: $1685-1691$.

6. Chadzinska M, Kolaczkowska E, Seljelid R, Plytycz B. Morphine modulation of peritoneal inflammation in Atlantic salmon and CB6 mice. J Leukocyte Biol 1999; 65: 590-596.

7. Brzezinska-Blaszczyk E, Venter D, Glinka R. Synthesis and pharmacological investigations of 1,2,3,4-tetrahydroisoquinoline derivatives. Pharmazie 1996; 51: 397-399.

8. Jozaki K, Kuriu A, Waki N, Adachi S, Yamatodani A, Tarui S, Kitamura Y. Proliferative potential of murine peritoneal mast cells after degranulation induced by compound 48/80, substance P, tetradecanoylophorbol acetate, or calcium ionophore A23187. J Immunol 1990; 145: $4252-$ 4256.

9. Levi-Schaffer F, Slovik D, Armetti L, Pickholtz D, Touitou E. Activation and inhibition of mast cells degranulation affect their morphometric parameters. Life Sci 2000; 66: 283-229.

10. Godfraind C, Louahed J, Faulkner H, Vink A, Warnier G, Grencis R, Renauld JCh. Intraepithelial infiltration by mast cells with both connective tissue-type and mucosal-type and mucosal-type characteristics in gut, trachea, and kidneys of IL-9 transgenic mice. J Immunol 1998; 160: 3989-3996.

11. Verbsky JW, McAllister PK, Malone DG. Mast cell activation in human synovium explants by calcium ionophore A23187, compound 48/80, and rabbit IgG anti-human IgE, but not morphine sulfate. Inflamm Res 1996; 45: $35-41$.

12. Chadzinska M, Scislowska-Czarnecka A, Plytycz B. Inhibitory effects of morphine on some inflammation related parameters in the goldfish Carassius auratus L. Fish Shellfish Immunol 2000; 10: 531-542.

13. Chadzinska M, Plytycz B. Differential migratory properties of mouse, fish, and frog leukocytes treated with agonists of opioid receptors. Dev Comp Immunol 2004; 28: 949-958.

14. Kolaczkowska E, Menaszek E, Seljelid R, Plytycz B. Experimental peritonitis amphibians is not suppressed by morphine treatment. Pol J Pharmacol 2000; 52: 323-326.

15. Bussiere JL, Alder MW, Rogers TJ, Eisenstein TK. Differential effects of morphine and naltrexone on the antibody response in various mouse strains. Immunopharmacol Immunotoxicol 1992; 14: 657-673.

Received 13 July 2004

Accepted 9 August 2004 


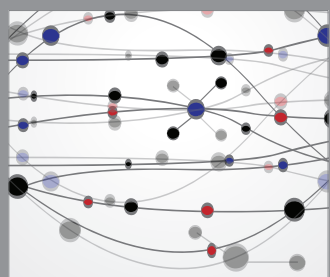

The Scientific World Journal
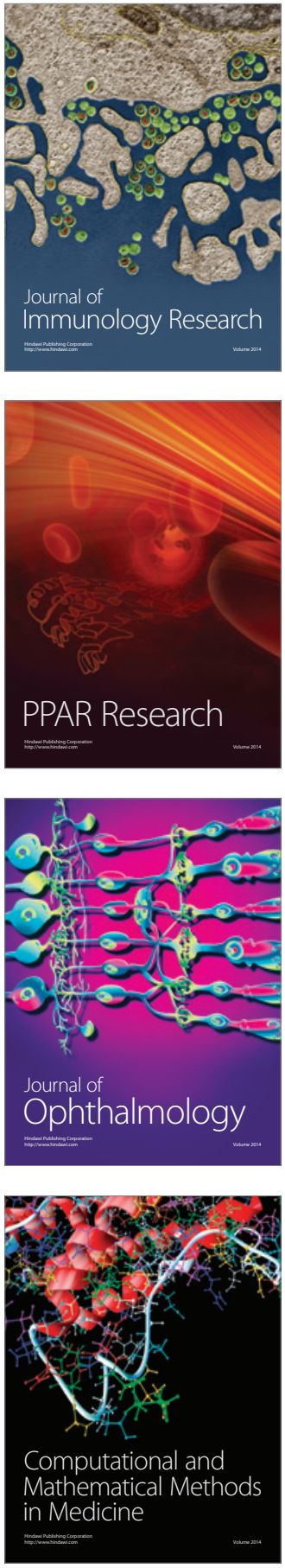

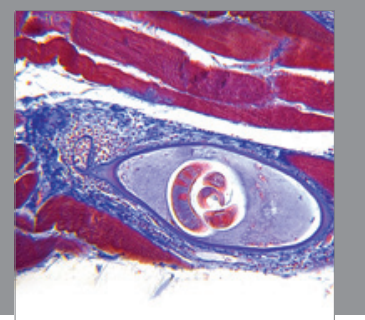

Gastroenterology

Research and Practice
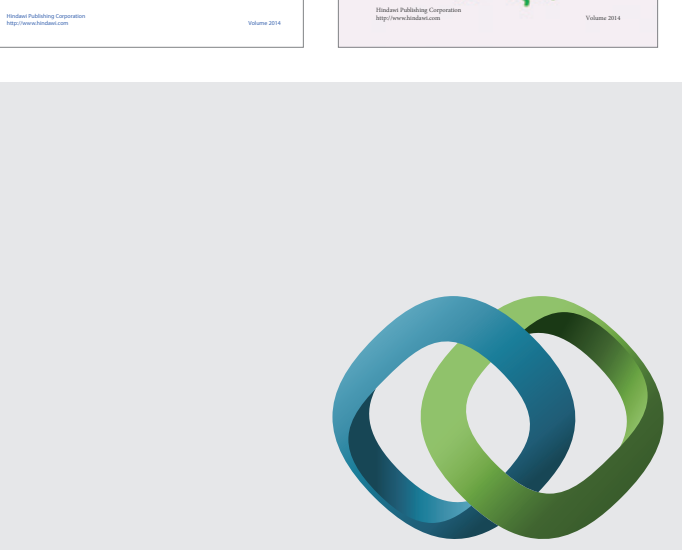

\section{Hindawi}

Submit your manuscripts at

http://www.hindawi.com
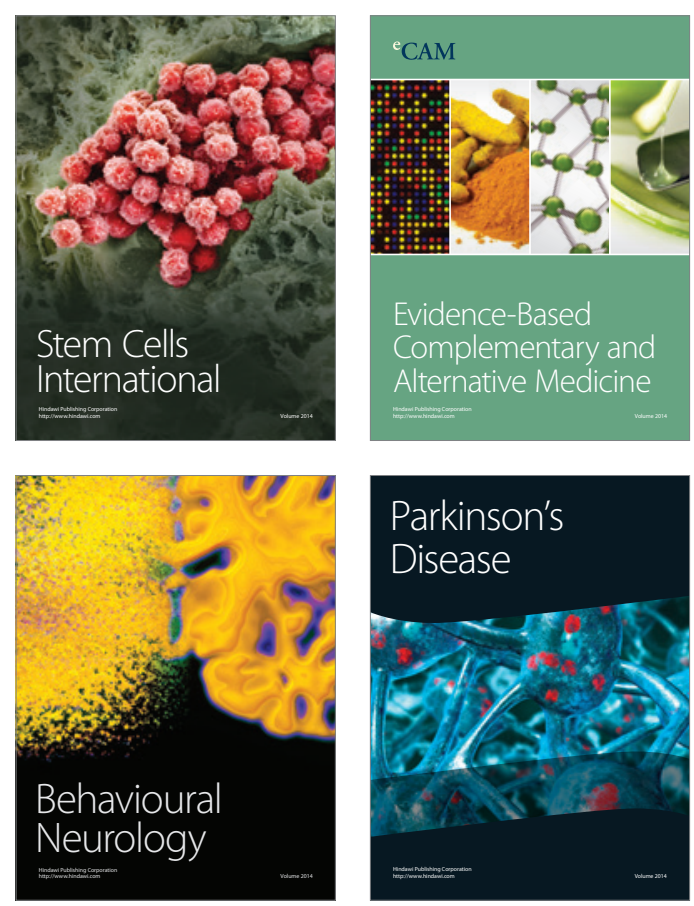

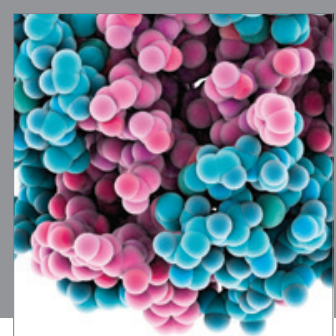

Journal of
Diabetes Research

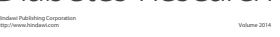

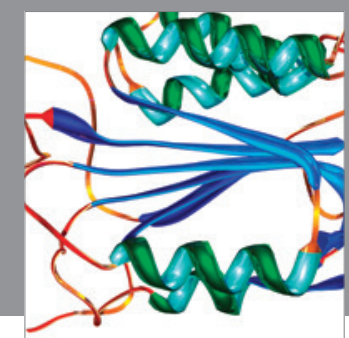

Disease Markers
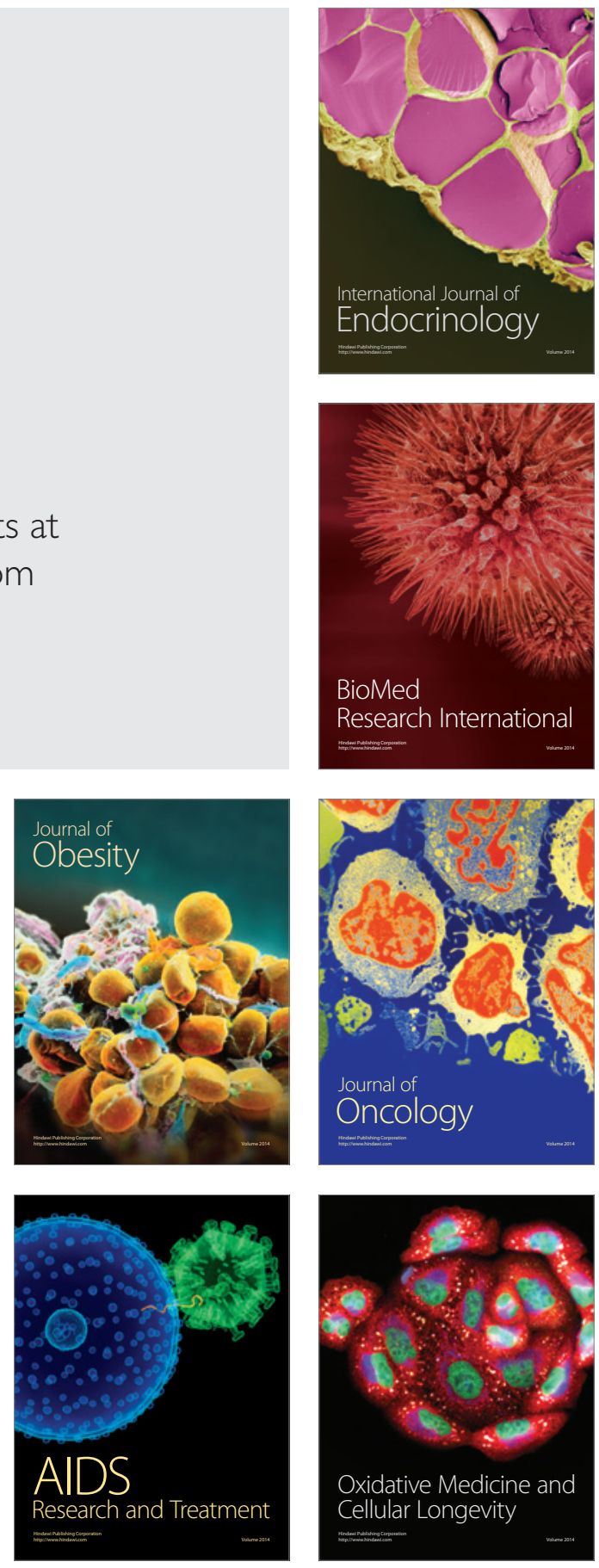